\title{
Did the market-clearing postulate pre-exist new classical economics ? \\ The case of Marshallian theory
}

\author{
M. De Vroey
}

Discussion Paper 2005-11

Département des Sciences Économiques

de I'Université catholique de Louvain 


\title{
Did the market-clearing postulate pre-exist new classical economics? The case of Marshallian theory
}

\author{
Michel De Vroey \\ April 2005
}

\begin{abstract}
Have new classicists invented market clearing or have they just rehabilitated it? This is the question addressed in the present paper. It is generally agreed that market clearing underpins Walrasian theory, so my exploration is limited to the question of whether this is also true for Marshallian theory. I will claim that this is broadly the case: once Marshallian theory is properly reconstructed, it exhibits market clearing as a constantly present result. Still, an important difference between market clearing à la Walras and market clearing à la Marshall exists: in the former market clearing $i$ s equilibrium, while in the latter market clearing can coexist with disequilibrium. Next, I investigate whether my conclusion extends to the labour market. Again the conclusion reached is affirmative both for Marshall's theory and for present-day Marshallian models. As to the latter, I take Friedman's Phillips Curve model as a case study. I show that this is a market clearing model in which, strictly speaking, there is no place for the concept of unemployment - quite an ironical result for the paper that introduced the notion of the natural rate of unemployment!
\end{abstract}

KEYWORDS: market clearing, equilibrium, Lucas, Marshall, Friedman JEL: B20, B40, D50

$\checkmark$ IRES, Université catholique de Louvain, 3 Place Montesquieu, 1348 Louvain-la-neuve, Belgium. E-mail address: devroey@ires.ucl.ac.be

This work was supported by the Belgian French-speaking Community (Grant ARC 03/08-302) and the Belgian Federal Government (Grant PAI P5/10). I am grateful to Franco Donzelli, Ivan Moscati and Luca Pensieroso for their critical remarks on earlier versions of this paper. 


\section{Introduction}

The "new classical revolution" has been one of the outstanding features of the development of economic theory during the last quarter of the twentieth century. The basic methodological precept associated with it is what Robert Lucas, one of its leading figures, has called the "equilibrium discipline". According to this, any valid economic reasoning must be based on two premises, that agents behave in an optimising way and that markets always clear. My interest in this paper lies with the second of theses postulates. The question that triggered it is "Have new classicists invented market clearing or have they just rehabilitated it"? No clearcut answer comes to mind. On the one hand, the label "new classicist" suggests that they advocate a return to a view held by earlier pre-Keynes classicists. On the other hand, no "old" classicist would have brought market clearing to the forefront in the way Lucas did nor would he or she have declared, as Lucas has, that it had the status of a postulate. Moreover, the term itself was probably not in use in classical times! This explains why commentators often take it for granted that market clearing is a new classical innovation.

Exploring the issue of whether market clearing was present in economic theory prior to Keynes is the aim of this paper. In principle such an investigation should bear on the two main streams of neoclassical theory, the Marshallian and the Walrasian approach. However, I will concentrate my attention on the former of these since few people would dispute the view that market clearing is an essential feature of Walrasian theory. ${ }^{1}$ The matter is more complicated when it comes to Marshallian theory. First of all, market clearing is a Walrasian concept, which is scarcely to be found in the writings of Marshall and Marshallian economists. So, before being able to assess its presence, the issue of whether it has some equivalent in Marshallian theory must be investigated. Moreover, the notion of market clearing is definitely related to that of equilibrium. Therefore, a clear understanding of the latter notion is a prerequisite. The problem here is that, although this notion plays a central role in Marshall's theory, its exact meaning is hard to decipher for, as is well known, Marshall was an ambiguous author who always shrank from presenting his views in any clear-cut way.

Three main points will be made. First, I will argue that the Walrasian notion of market clearing definitely has a correspondent in Marshallian theory, namely Marshall's notion of market-day equilibrium (in short market equilibrium). Second, I will claim that market clearing is always present in Marshallian theory. This is true for Marshall's Principles (1920), with a few qualifications. It is also true for later Marshallian literature, at least as far as can be judged from the writings of an emblematic modern Marshallian economist, Milton Friedman. My third point relates to a difference between the Walrasian and the Marshallian approaches.

\footnotetext{
1 Commentators such as Walker (1966) who tilt Walras towards Marshall are the exception.
} 
While in the former market clearing and equilibrium are part and parcel of each other, this is not true for the latter, where market clearing can be separated from equilibrium. The belief that non-market clearing is a normal outcome in the Marshallian approach would then be due to a mistaken identification of of market clearing with equilibrium.

Why enter into such an inquiry? Two reasons can be put forward. The first, already evoked above, is that, in view of the present-day prevalence of the Lucasian conception of equilibrium, it is worth assessing its originality. Second, such a discussion has deeper implications. To understand this, it is easier to refer to the opposite of market clearing, market non-clearing or market rationing - two terms that will be used interchangeably - i.e. states where the market closes with an excess of supply over demand. One market for which such a possibility is of particular importance is the labour market. If my claim is granted, it means that unemployment is as absent from standard Marshallian theory as it is from economic theory à la Lucas!

In Section 2, I recall the contents of the "equilibrium discipline". Sections 3 and 4 deal with two prerequisites, the distinction between the logical existence and the formation of equilibrium, on the one hand, and the definition of market clearing, on the other. In Section 5, I present my reconstruction of the Marshallian conception of equilibrium. I also explain why the Marshallian concept of market equilibrium can be considered the equivalent of the Walrasian market-clearing concept. In Section 6, I claim that, once Marshallian theory is properly reconstructed, it exhibits market clearing as a constantly present result. Still, an important difference between market clearing à la Walras and market clearing à la Marshall exists: in the former market clearing is equilibrium, while in the latter market clearing can coexist with disequilibrium. Discussions about market clearing are particularly relevant when it comes to the labour market. Therefore, I explore in Section 7 whether my conclusion about the presence of market clearing in Marshallian theory also applies to the labour market. I argue that this is the case, at least as far as Marshall's value theory is concerned. While unemployment did find some place in his work, it was confined to business cycle and monetary theory, theoretical domains that had only a loose connection with value theory. In Section 8 , I consider whether the same conclusion still holds for more recent works, taking Milton Friedman's Phillips Curve model as a case study.

My interest in this paper is in Marshall the value or equilibrium theorist, that is, in the views he expounded mainly in Books III and V of the Principles. I am well aware that this is not the Marshall preferred by many of his followers, such as Clower and Leijonhufvud (Clower and 
Leijonhufvud ([1975] 1984) or indeed most present-day Marshallian scholars. ${ }^{2}$ Still, it is the part of his work that has been the most influential, leaving its imprint in microeconomics textbooks and shaping economists' standard way of thinking. Even when the scope of Marshallian theory is narrowed down in this way, some rationale reconstruction is still needed. It is the fate of authors, such as Marshall, who manifested 'impatience with rigid definitions' to borrow from Guillebaud (1942: 333), that their interpreters have to fill in the loopholes in their reasoning. Since there is more than one way to do this, it is no wonder that no unanimity exists among Marshallian scholars.

\section{The equilibrium discipline}

By initiating the downfall of standard IS-LM macroeconomics and its replacement by a new type of modelling, stochastic dynamic macroeconomics, Lucas has probably been the most important economist of the last quarter of the twentieth century. The change that took place was not only of substance, it was also methodological.

Lucas central methodological claim is that economic theory needs to respect what he calls the "equilibrium discipline", that is, it must be based on the postulates of optimizing behaviour and market clearing (Lucas Sargent ([1979] 1994: 58). ${ }^{3}$ As to market clearing,

[It] is simply a principle, not verifiable by direct observation, which may or may not be useful in constructing successful hypotheses about the behaviour of these series. Alternative principles... are similarly 'unrealistic', in the not especially important sense of no offering a good description of observed labour market institutions (Lucas and Sargent [1979] 1994: 21). 4

When it comes to explaining how market clearing may come about within the context of the Walrasian approach, the lineage adopted by Lucas, the usual story is the auctioneer scenario. It is based on the assumption that there exists an outside market secretary, who announces prices and allows trade to take place once equilibrium has been reached. Most economists referring to the auctioneer do so only grudgingly because it is difficult to deny that the

\footnotetext{
2 See, for example, Arena and Quéré (2003) and Leijonhufvud (1998).

3 A critical assessment of the equilibrium discipline can be found in De Vroey (2004a).

4 As Lucas stated in an interview with Snowdon and Vane, "I think general discussions, especially by noneconomists, of whether the system is in equilibrium or not are almost entirely nonsense. You can't look out of this window and ask whether New Orleans is in equilibrium. What does that mean? Equilibrium is a property of the way we look at things, not a property of reality". (Snowdon and Vane, 1998: 127). This point has escaped many commentators who instead have presumed that Lucas was making a claim as to the real-world existence of market clearing. See e.g. Malinvaud (1984: 18), Grandmont (1983: 2), Solow (1990: 28), Lipsey 2000: 72).
} 
auctioneer is more of a deus ex machina than a plausible representation of market forces, more a way of sidestepping the issue of the functioning of markets than a solution to it. But then no alternative stories are available. Admitting that market clearing ought to be considered a postulate and resorting to the basically inappropriate yet convenient auctioneer hypothesis are thus the two sides of the same coin.

Lucas' and his fellow authors have been fully consistent in their methodological stance: market rationing is absent from their models. This is especially true for unemployment, the most significant case of market rationing. It plays no role in their main contribution to economic theory, the equilibrium modelling of the business cycle.

In most such models [of the business cycle] unemployment as a distinct activity plays no role whatever. For many other economists, explaining the business cycle is taken to mean accounting for recurrent episodes of widespread unemployment. From this alternative viewpoint, a model with cleared markets seems necessarily to miss the main point, however successful it may be in accounting for other phenomena, and the work of 'equilibrium' macroeconomists is often criticized as though it were a failed attempt to explain unemployment (which it surely does fail to do) instead of as an attempt to explain something else (Lucas 1987: 48).

\section{The logical existence of equilibrium and the formation of equilibrium: two distinct issues}

Whatever the conception of equilibrium held, two different objects of study must be distinguished: the determination of equilibrium and its formation. The former aims at ascertaining the logical existence of an equilibrium solution making economic agents' plans compatible. The question of how the equilibrium might be brought about is the second object of study: it being admitted that equilibrium exists logically, how can it become established as the result of agents' interactions? The first of these two issues has received most attention from economists, yet completeness requires the second to be tackled as well. 5

The determination/formation of equilibrium distinction underpins Walras's Element of Pure Economics (1954). Walras's overall aim was to demonstrate the efficiency of a competitive economy. Achieving this aim, he realised, implied two solutions, a theoretical or

\footnotetext{
5 No fixed terminology exists here. Jaffé, the translator of Walras's Elements of Pure Economics, calls what I call 'formation' 'emergence' or 'establishment'. He characterises the distinction in the following terms: "The laws of the emergence or establishment of equilibrium prices refer to the laws of those operations of the market that result in equilibrium, whereas the laws of the determination of equilibrium price take into account the ultimate facts and forces which constitute that price" $(1954$, p. 501).
} 
mathematical one and a practical one. The latter consisted of demonstrating that the operation of competition in the economy produced a solution which was identical to the theoretical one (1954: 106). Walras's theoretical solution corresponds to what I call the issue of the determination of the logical existence of equilibrium, his practical solution to what I call the formation of equilibrium. To him, the issue of the logical existence of equilibrium took the upper hand over that of its formation. In the process of revising the Elements, he became gradually aware of the fact that allowing out-of-equilibrium trading led the economy to converge to a state of equilibrium different from that obtained when studying equilibrium from its logical existence angle. Facing such a lack of coincidence between the theoretical and the practical solutions, he excluded any out-of-equilibrium trading in order to maintain the coincidence, thereby making his tâtonnement assumption totally unrealistic.

Marshall's standpoint was the opposite although the distinction between the determination and the formation of equilibrium was only implicitly present in his work. In the barter appendix in which he analyses the exchange between apples and nuts (1920: 791-3), he distinguishes between two notions of equilibrium, "true equilibrium" and "accidental equilibrium". While he does not bother to define them, true equilibrium corresponds to Walras's theoretical or mathematical solution: it is the equilibrium calculated by outside economists pondering upon the logical existence of equilibrium. The accidental equilibrium also belongs to the logical existence inquiry. It refers to any equilibrium result - an equilibrium in that it is a state where all possibilities of mutual gain have been exploited different from the true equilibrium. The main point, however, is that Marshall's priority was the study of the formation of equilibrium. Unlike Walras, he had little interest in demonstrating the logical existence of equilibrium, and contented himself with assuming that a true equilibrium existed.

\section{Defining market clearing}

Market clearing is a Walrasian concept. It belongs to a broader picture in which the economy is viewed as a succession of points in time, each of which is associated with a tâtonnement process directed by the auctioneer. Market clearing refers to the outcome of a given trade round and designates a state where the excess demand for every good is equal to zero, which indicates that the equilibrium price vector has been arrived at. 6 As to the choice of this terminology, in his microeconomics textbook, Perloff gives the following justification: "the

\footnotetext{
6 A positive excess demand can exists if the numeraire price of the good is equal to zero, the case of 'free goods'.
} 
equilibrium price is called the market clearing price because it removes from the market all frustrated buyers and sellers" (2001: 29).

A more formal definition can be found in any microeconomics textbook. Take for example, Mas-Colell, et al. (1995: 314). They consider an economy consisting of consumers indexed by $i=1, \ldots I$ firms indexed by $j=1, \ldots J$ and goods indexed by $l=1, \ldots L$. Together with profit maximization and utility maximization, market clearing is a condition for Walrasian equilibrium (i.e. an equilibrium allocation and an equilibrium price vector). That is, for each good $l$,

$$
\sum_{i=1}^{I} x_{l i}^{*}(\mathbf{P})=\omega_{l}+\sum_{j=1}^{J} y_{l j}^{*}(\mathbf{P}),
$$

where $\omega_{l}$ is the total endowment of $\operatorname{good} l, x_{l i}$ is the consumption of $\operatorname{good} l$ by agent $i, y_{l j}$ is the production of good $l$ by firm $j$, and asterisks indicate equilibrium values, $x_{l i}$ and $y_{l j}$ being functions of the price vector $(\mathbf{P})$.

Market clearing is point-in-time equilibrium - in a given trade round all agents' optimising plans, pertaining to production and trade, have been made compatible. This equilibrium exists both at the interactive level (production and trade plans are made compatible) and at the individual level (agents see their optimising plans come through). Market non-clearing is synonymous with disequilibrium. Yet, in this framework states of disequilibrium only have a virtual existence since they are eliminated by the auctioneer before the opening of trade. 7

The notion of market clearing can also be approached with reference to the determination/formation distinction. It has been seen above that Walras was aware of the need for the theoretical and practical solutions to the problem of equilibrium to coincide. This has a direct bearing on the definition of market clearing. For a given market outcome to qualify as market clearing, it must be identical to the outcome calculated by the economist when analysing the logical existence of equilibrium.

\footnotetext{
7 Market clearing is only one of the two elements composing Walrasian theory, as it pertains to an economic outcome arising at one point in time. The intertemporal behaviour of the economy, its evolution across trade rounds, is the other element. While Walras broached this briefly in his credit model, its basic conceptualization is due to Hicks in his Value and Capital (1939). Faithfully to Walras, Hicks considered that market clearing prevailed at each point in time (although he changed his view on this point later on), but admitted that the economy might depart from its intertemporal equilibrium path, thereby making the notion of disequilibrium relevant for designating such departures (1946: 132). However, authors such as Lucas have refused to tread in Hicks's footsteps in this respect.
} 


\section{The Marshallian conception of equilibrium}

Well aware of the importance of time for economics, Marshall was keen to associate time and equilibrium. Yet, as was often the case with him, ambiguities kept looming. With hindsight, two rival interpretations of his views on equilibrium and time prove possible.

According to the standard interpretation, Marshall held three distinct concept of equilibrium, each of which could be the subject of a separate analysis: market equilibrium (or ultra-short equilibrium), short-run equilibrium and long-run equilibrium. ${ }^{8}$ The drawback of this conception is that the links between the time periods remain in the dark, no hint being given as to how to piece them together. An alternative interpretation, my preferred one and the one to which I shall stick henceforth, consists of putting Marshall more firmly in the lineage of the classical standstill-gravitational conception of equilibrium by reducing these three categories to two, which, moreover, are now viewed as organically linked. When this line is taken, the Marshallian conception inherits two features of the classical conception. The first is that two equilibrium concepts are present - in the classical universe, market prices equilibrium and normal prices equilibrium, in the Marshallian, market equilibrium and normal equilibrium. ${ }^{9}$ The second feature is gravitation. The two equilibrium concepts are in a relationship of hierarchy with normal equilibrium being the higher or more fundamental concept and market equilibrium the lower or less fundamental one. That is, market equilibrium will gravitate around normal equilibrium and the market will come to a standstill only when the market equilibrium values (i.e. quantity and price) coincide with the normal equilibrium values.

Normal equilibrium exists whenever the market outcome in a given branch is such that firms lack any incentive to change their behaviour, any previous decision to change behaviour having been finalised (Marshall's attention focused more on firms than on households). As soon as market equilibrium values fail to coincide with normal equilibrium values, disequilibrium can be said to prevail. Market equilibrium indicates that agents' plans have been made compatible, the quantity produced being given. This duality of equilibrium concepts translates into a duality of adjustment processes and supply and demand functions.

\footnotetext{
8 See, for example, Hicks (1939), Stigler (1946) or Frisch (1950). In Stigler's words, “One of Marshall's greatest contributions to economic theory was the discovery that the pricing problem should be treated primarily from the point of view of time. He distinguishes three fundamental time periods in pricing: 1) market prices - the price of a commodity during a period in which its supply is fixed; 2) short-run normal price - the price of a commodity during a (longer) period in which the rate of production (per unit of time) is variable, but in which there exists a fixed plant; 3) long-run normal price - the price of the commodity during the period in which the rate of production is completely variable, a fixed plant no longer existing" (Stigler 1946: 147).

9 The distinction between the short and the long period is still present yet each of these is now considered a subcase of normal equilibrium.
} 
Adjustment towards normal equilibrium occurs across market days while adjustment towards market equilibrium occurs within a given market day. ${ }^{10}$ As to supply and demand functions, normal equilibrium pertains to the matching between normal supply and demand, market equilibrium to the matching between market supply and demand.

The result of this duality of equilibrium concepts is that three rather than two outcomes are conceivable: (a) it can be the case that both equilibrium concepts are satisfied; (b) it can also be the case that none of them is fulfilled; (c) finally, market equilibrium may turn out to exist in combination with a lack of normal equilibrium. The first case could be called 'full equilibrium' and the second 'full disequilibrium', the term 'disequilibrium' tout court being reserved for the third occurrence. This last appellation follows from the fact that normal equilibrium is more important than market equilibrium. Hence the market should be considered in disequilibrium as long as normal equilibrium fails to prevail even if market equilibrium is present. 11

I am now able to address the question of what the equivalent of the Walrasian notion of market clearing is in the Marshallian universe. This boils down to the question of which of the two equilibrium concepts in Marshall's theory market clearing should be associated with? The spontaneous answer is 'full equilibrium', in which case the issue of the permanent achievement of market clearing in Marshallian theory could be answered at once - in the negative. Yet there is no logical reason for such an association, which is too demanding. The very existence of two equilibrium concepts allows market clearing to be given a more limited scope, designating one of the two possible outcomes of a given trade round, while leaving any assessment of the deeper equilibrium nature of this outcome for the theory of the formation of normal equilibrium.

If this point of view is adopted, market clearing can be stated to exist in the Marshallian approach whenever market supply and demand end up matching in a particular market on a given market day - in other words, when the quantity and price observed at the end of the market day coincide with the logically existing (or true equilibrium) magnitudes. 12

\footnotetext{
10 The Marshallian and Walrasian approaches have in common the assumption that trade is confined to welldelineated trade rounds. In Walrasian theory, the trade round is associated with a given dated tâtonnement process, in Marshallian theory with the market day. Both conceptions can be subsumed into Hicks' 'week' device, where trade takes place exclusively on Mondays.

11 The cobweb model is a good example of states of disequilibrium-cum-market equilibrium.

12 A further lesson to be drawn is that that the notion of disequilibrium is understood differently in the Walrasian and the Marshallian approach. In the Walrasian approach, disequilibrium exhibits two features: first, it is the opposite of market clearing and, second, it has only a virtual existence. In contrast, in the Marshallian approach, disequilibrium can coexist with market clearing and has an effective existence.
} 


\section{Assessing the existence of market clearing in Marshall's Principles}

Our next step is to investigate the characteristics of market equilibrium in Marshallian theory. Is it always realised? Or is market disequilibrium a conceivable outcome? And, if always realised, is this because market clearing has been postulated or does it result arise endogenously from the operation of the market? These are the issues addressed in this section. To elucidate them, I turn to Book V Chapter II of the Principles (in which Marshall examines the operation of a daily corn market in a small provincial town) and to his barter appendix.

Let me start with the barter appendix. Here Marshall makes the point that there is little chance of arriving at a true equilibrium in a barter context. The culprit is the income effect. Most probably, trade will start at a false price, i.e. at a price different from the true equilibrium price. This will change agents' endowments, which in turn will lead them to modify their trade offers. Path dependency crops up. Trade will stop when all opportunities for mutually beneficial exchanges are exhausted, yet this end result is an accidental equilibrium, not the true equilibrium. The underlying factor is that the two goods exhibit a decreasing marginal utility. Fortunately enough, this negative conclusion ceases to be valid when the exchange becomes monetary - that is, in his apples-nuts example, if nuts are considered as the monetary good - since in a monetary economy it can be assumed that money has a constant marginal utility. This feature itself results from another assumption, that an agent's expenditure in the market in point be small relative to his or her total expenditure. Path dependency being thereby eliminated, the exchange process will end up at the true equilibrium position even if false trading is accepted. More precisely, the total quantity of apples exchanged will be the same as it would have been without false trading, and the final price will correspond to the true equilibrium price. The distribution of nuts will however be different from what it would have been otherwise.

The same argument underpins Marshall's analysis in Book V Chapter II of the Principles where, after having first evoked the view that the attainment of true equilibrium resulted from agents' perfect knowledge of the circumstances of the market, Marshall again takes up the constant marginal utility of money assumption. The result of this (on top of Marshall's general assumption of an additive utility function) is that the quantity sold and the final price will coincide with the true equilibrium values (700 quarters, 36 shillings.)

It is not indeed necessary for our argumentation that any dealers should have a thorough knowledge of the circumstances of the market. Many of the buyers may perhaps underrate the willingness of the sellers to sell, with the effect that for some time the price rules at the highest level at which buyers can be found; and thus 500 quarters may 
be sold before the price sinks below 37s. But afterwards the price must begin to fall and the result will still probably be that 200 more quarters will be sold, and the market will close on a price of about 36s. For when 700 quarters have been sold, no seller will be anxious to dispose of any more except at a higher price than $36 \mathrm{~s}$., and no buyer will be anxious to purchase any more except at a lower price than 36s. (Marshall, 1920: 334) 13 This groping scenario produces a result that is close to the realisation of the true equilibrium with more acceptable assumptions: the quantity of corn traded is the same as in true equilibrium, and the price of corn in the last transaction is the same as in true equilibrium. However agents end up with different money balances. This scenario is appealing because it conveys the idea of trial and error, a central feature of a decentralised market. It is then small wonder that most commentators (e.g. Hicks (1965), Dasgupta (1990) and Negishi (1989)) have bestowed high praise on Marshall for his false trading analysis. To all these authors, this explanation is the core of Marshall's corn model, the general plausibility of the constant marginal utility of money assumption remaining unquestioned.

I, however, have a more critical judgement of Marshall's reasoning since I am of the opinion that this assumption is ad hoc. First, it cannot be asserted in general that all expenditures represent a small proportion of an agent's total income. Just think of markets for durable goods. Second, the generalisation from partial to general equilibrium analysis becomes very difficult, if not impossible, with such an assumption. It would be necessary to establish the order in which consumers visit markets, and it would turn out that the constant marginal utility of money would become less and less valid as the number of markets which remain to be visited falls. Third, the assumption may be plausible as far as the demand side is concerned (and moreover only the demand for a certain range of consumer goods), but what about suppliers, especially when the latter are firms? Fourth, if the idea of a well-delineated trade round is to be retained, what guarantees are there that the bargaining process will come to an end before the end of the time span allotted to trading?

Actually, there is an alternative to the constant marginal utility of money assumption. In effect, earlier in the same chapter Marshall invokes another channel, already alluded to above, through which true equilibrium can emerge, namely agent's perfect knowledge of the market circumstances.

13 For modern expositions of Marshall's point, see Newman (1990) and Mas-Collel, Whinston and Green (1995). 
The price of 36s. has thus some claim to be called the true equilibrium price: ...; and because every dealer who has a perfect knowledge of the market expects that price to be established (1920: 333).

This quotation is somewhat puzzling. It is true by definition that any perfectly informed agent will know the true equilibrium price. Yet the knowledge of the true equilibrium price by some agents is not a sufficient condition for its realization. A further step is needed, to move from Marshall's assertion that some dealers have foreknowledge of the market outcome to the stronger assertion that every dealer is endowed with this foreknowledge. If this is the case, every supplier will be ready to trade at a price higher than 36 shillings, and every consumer at a lower price, yet under these conditions no one will find a trading partner. Hence the only price at which trading will take place is 36 shillings. Thus, if Marshall's statement is reconstructed in this way, market equilibrium turns out to be arrived at as the result of agents' ability to form correct conjectures as to the equilibrium values.

At first sight, this perfect information assumption does not look too worrying - at least, it looks less worrying than the auctioneer assumption. If markets are small, the total amount of information agents have to master is manageable. Moreover, Marshall supposes a stable, if not unchanging, world. There are basic facts of business which remain unchanged and which agents can use in decision-making. The assumption that agents have perfect knowledge seems an admissible way of capturing the view that traders are experienced, acute and quick learners.

However, upon closer scrutiny a less sanguine conclusion emerges. Among the several objections that can be addressed to the perfect information assumption, I shall limit myself here to the most important one. It has the flaw of running counter to a basic trait of a decentralised economy, namely that it is a private economy, the private term applying not only to ownership but also to information. The crucial issue is how agents might come to know market supply and demand functions. Clearly, the outside economist is able to assess them, yet why would this also be true for the inhabitants of the model, the economic agents? We, Marshall's readers, may well have a supply and demand graph before our eyes, yet the agents within the model do not! In order to be able to reconstruct it, they would have to be cognoscenti of the private data (preferences, technological constraints) that underpin individual supply and demand functions. But why should these data become common knowledge? It is in every agent's interest to refuse to communicate them to other agents. In short, adopting the perfect knowledge assumption amounts to blurring the level of knowledge 
of the omniscient outside economist and that of the economic agent. ${ }^{14}$ First impressions to the contrary notwithstanding, the omniscient agents assumption is as much a deus ex machina as the auctioneer.

In Marshall's defence, it can be argued that this defect is less dramatic than it might appear at first sight. Had Marshall not been Marshall, and had he been ready to admit the central role played by perfect information in his theoretical construct, he might have defended it by arguing that the overarching aim of his theory of value was to provide a theory of the working of competition. Such a theory would focus on the formation of normal equilibrium with respect to which the formation of market equilibrium is peripheral. In other words, Marshall might have claimed that the way in which markets function daily is of lesser importance than how they adjust over time. Add to this the fact that explaining their daily functioning in a general way proves to be a daunting task. If a task is at the same time daunting and of secondary importance, it is better to put it aside by summoning a deus ex machina so as to direct the investigation towards the most important issue.

Be that as it may, it turns out that Marshall had two irons in the fire. When it came to addressing the issue of how markets functioned, he proposed the false trading/constant marginal utility of money story with its undeniable advantage of coming closer to picturing the functioning of the market in a decentralised fashion. Yet, for all its appeal, this scenario has no general validity. Marshall's second, less ostentatious, iron in the fire was the assumption that agents were omniscient. Evidently, this assumption can be useful, but only in the same way as the auctioneer, by dodging an intractable issue.

When the inquiry is limited to the issue of how market equilibrium is obtained in a particular market, the first line is admissible. But it cannot do when it comes the more important subject of how markets adjust over time, that is, the study of the formation of normal equilibrium. Although still a far cry from a general equilibrium model, such an analysis necessarily comprises an element of interdependency since production decisions hinge on the market conditions prevailing in the factors markets. At this stage of the theory, the false trading story no longer works, and in effect it vanishes from Marshall's theory. Admittedly, the perfect information scenario still receives little recognition - this would be too much to ask from Marshall and Marshallian economists tangled up in their concern with realism. Yet, with the

\footnotetext{
${ }^{14}$ This point was emphasised long ago by Hayek ([1937] 1948). The canonical Walrasian model is also based on the assumption of perfect information yet its domain of relevance is smaller than in the Marshallian case, because of the existence of the auctioneer. His presence has the straightforward implication that agents do not need to be cognoscenti of supply and demand functions, and hence of the private preferences underpinning these functions. See De Vroey (2003) for further discussion of this point.
} 
constant marginal utility of money no longer being invoked, perfect information remains the only available explanation. 15

\section{Unemployment}

Of all possible markets, there is one for which the claim that the idea of market rationing is banished from Marshallian theory seems particularly inappropriate, and that is the labour market. Should this be an exception to my general conclusion? My answer is in the negative: the Marshallian canonical model has no place for unemployment.

Although no systematic analysis of the labour market is to be found in the Principles, Marshall made scattered remarks about it. These pertained to the particularities of the demand for and supply of labour. But he never took the further step of studying how these particularities impinged on the working of the labour market. ${ }^{16}$ Silence is consent. The bottom line must be that, to Marshall, the labour market operated on the same principles as the corn market, in which case it could not be an exception to the market clearing principle.

Whenever Marshall discussed unemployment, he related it to low human capital, sectorial shifts in employment and the business cycle. As noted by Matthews (1990),

Cyclical unemployment was par excellence a 'Vol. II' subject, along with business cycles generally. It does get some treatment in the Principles, but to a large extent Marshall's views have to be pieced together from his various writings. Those are often fragmentary or aphoristic. (Matthews 1990: 35)

According to Matthews (1990), Marshall's limited interest in unemployment could be explained by social context. ${ }^{17}$ For my part, I think that an additional explanation, of a more

15 "But though everyone acts for himself, his knowledge of what others are doing is supposed to be generally sufficient to prevent him from taking a lower or paying a higher price than others are doing. This is assumed provisionally to be true both of finished goods and f their factors of production, of the hire of labour and of the borrowing of capital" (Marshall 1920: 341). For a more in-depth analysis, again, see De Vroey (2003).

16 Marshall also asserted that the constant marginal utility of money assumption was inappropriate as far as labour was concerned.

17 In Matthews's words, "Unemployment, particularly in combination with inflation, has made the functioning of the labour market a central topic in present-day economics. Unemployment has been judged as both intellectually anomalous and a social challenge. This emphasis is absent in Marshall. The social problem that disturbed his conscience was poverty; and poverty might have a number of causes, of which unemployment was only one. Marshall usually discusses unemployment under the designation 'inconstancy of employment', implying that people affected do have work some of the time. This was realistic. The social security system that prevailed at the time the Principles was written scarcely allowed an able-bodied man to stay wholly without earnings for years at a stretch. Marshall had therefore no need to address himself to the problem of persistent long-term unemployment. But even a limited spell of unemployment could be a serious source of poverty for a working class family, given its low financial reserves, and it could cause a 'nasty notch' in the nurture of its 
methodological nature, is in order. I view Marshall as subscribing to a methodological practice which held sway until recently - more precisely, until the rise of equilibrium models of the business cycle. It consists of dividing economics into two broad sub-fields: value theory, dominated by equilibrium principles, where market clearing always obtains; and business cycle theory, where monetary disturbances are supposed to play a central role and which is divorced from those principles. The notions of equilibrium and disequilibrium may still be evoked, but their use is more metaphorical than analytical. The problem is of course how to reconcile these two strands. As long as it is adopted, economists cannot but exhibit split personalities. When wearing their value theory hat, they need to exclude rationing in general (and unemployment in particular) from their discourse, whereas they have no qualms about such outcomes when speaking as business cycle theorists. This is, I suggest, the situation in which Marshall unwittingly found himself.

The above consideration explains why two outwardly opposite statements are both valid, that the category of unemployment is present in Marshall's theoretical work; and that the standard Marshallian model of the labour market features market clearing in the same way as the corn or the fish market, and has thus no place for unemployment! Of course, this proved to be an awkward position for the first generation of Marshallian economists (e.g. Pigou) to hold. A few way-outs were considered - the exogenous wage floor hypothesis, sluggish wages, market imperfections - yet to little avail. While the mandatory wage idea was too trivial a solution, the other two lacked a theoretical foundation. No clear indication was provided as to how they could occur within the basic Marshallian exchange model. With hindsight, this is no wonder, not because the idea of friction makes no sense but rather because (as modern search models make clear ) its theorisation requires a framework different from the standard Marshallian trade organisation,.

Finally, it must be noted that my claim that unemployment has no place in the standard Marshallian labour market involves no exclusion of labour market disequilibrium. The latter will simply take the form of over- or under-employment, a departure from the level of employment associated with normal equilibrium.

children. Nonetheless Marshall was inclined to think that the problem was exaggerated or at least that it was a mistake to suppose that it had got worse over time, or that it was worse than it had been for many workers in preindustrial times." (1990: 33-34) 


\section{Unemployment in the writings of modern Marshallian authors: the case of Milton Friedman 18}

Should the above conclusion about exclusion of unemployment be extended to more recent works, which in one way or another can be traced back to Marshall? Since a systematic study of this issue is beyond the scope of this article, I will content myself with examining the case of an author who can be considered the emblematic modern Marshallian economist, Milton Friedman. My concern here is with his influential Presidential Address on the Phillips Curve (Friedman 1968). Friedman's overall argument in this paper is well known. Therefore, I shall concentrate my attention on the precise point that I wish to make.

Friedman has recurrently proclaimed his Marshallian affiliation. It may thus be safely assumed that his Phillips Curve model belongs to the Marshallian approach. We have seen that the canonical Marshallian model has no place for unemployment. Yet Friedman's paper became famous for having introduced the notion of a natural rate of unemployment. This discrepancy can be interpreted in two ways: either Friedman's model turns out to be an amendment of the canonical Marshallian model, the result of which being that the excluded concept becomes acceptable; or it should be concluded that Friedman fell prey to the not so unusual flaw of pasting a non-Marshallian narrative onto a Marshallian model. I shall argue that this is indeed the case. Possibly because of its nature as a Presidential Address, Friedman's 1968 paper is a narrative without explicit model. Yet an implicit model is definitely present. It is made explicit in Friedman's Price Theory textbook (1976, 221 seq.). Figure 1 reproduces its central graph.

\footnotetext{
18 This section draws on De Vroey (2001).
} 
Figure 1. Friedman's labour market with workers' misperceptions

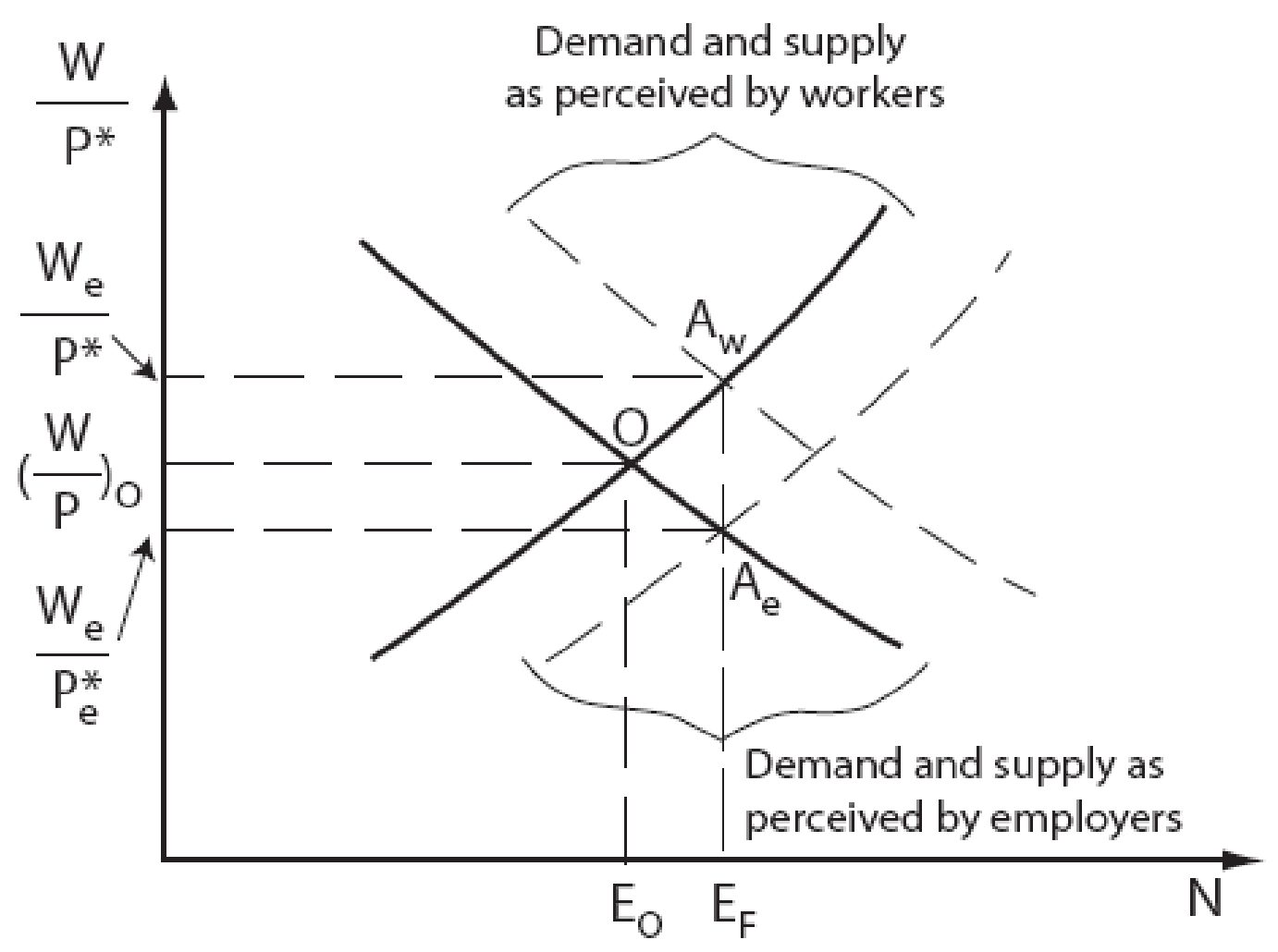

Whenever inflation is absent, Friedman's reasoning runs, everything proceeds smoothly. Before entering the market, all participants know its equilibrium values, the coordinates of 0 in the graph. The market outcome $\left(\mathrm{E}_{0}\right)$ corresponds to what Friedman calls the natural rate of unemployment, an appellation that I will declare misplaced below. However, as soon as inflation enters the picture, as the result of the monetary expansion, a different outcome surfaces. Consider the first trading round at which the impact of monetary expansion becomes visible in the labour market. Employees develop a false conjecture about the prices of goods, the result of their adaptive expectations. Failing to anticipate that a rise in price is going to 
occur in the consumer goods markets, they expect that a higher real wage will be associated with a higher nominal wage. On the basis of this conjecture, they mentally construe the new market equilibrium as the intersection $\left(\mathrm{A}_{\mathrm{W}}\right)$ of the new perceived demand curve and the unchanged supply curve. They are ready to trade at a higher employment/nominal wage mix. ${ }^{19}$ As to firms, they are aware of workers' misperception. They realise that it is tantamount in its effect to a change in workers' preferences. Hence they are ready to go down their demand curve to the point of intersection with the shifted supply curve, Ae. ${ }^{20}$ Endowed with their respective conjectures about the market equilibrium values, workers and firms come to the market with an exchange proposal that happens to involve the same increased quantity of labour traded $\left(\mathrm{E}_{\mathrm{F}}\right)$ and the same nominal wage (not on the graph). Exchange on this basis is possible and will take place.

This is Friedman's model of the labour market. Several comments are in order. First, in Friedman's reasoning, the formation of labour market equilibrium involves workers and firms needing and being able to assess the market demand and supply schedules - and hence their intersection - on their own. This confirms my claim above that agents' ability to mentally reconstruct market supply and demand functions is the key factor in explaining the formation of market equilibrium. "To the workers, it will appear as if the demand for labour has shifted to the right...". "For employers as a whole, it will appear as if the supply curve had shifted to the right..." These sentences make sense only if the formation of equilibrium results from agents' ability to assess market supply and demand functions. Though Friedman does not stress it - and possibly might not have realised it - his reasoning rests on the premise that the agents in the model are as knowledgeable about it as the outside omniscient economist, except for one aspect, workers' misperception, which is nothing more than a minimal change to it. ${ }^{21}$ Second, looking at Friedman's graph, we can observe that his model features market clearing: market-day supply of and demand for labour are equal and amount to 0-EF. In other words, nothing in his graph points to the existence of market rationing, i.e. unemployment.

\footnotetext{
19 "As yet they have no reason to suppose a change in the price level, hence they have no reason to change their supply function. It will remain the solid supply curve on Figure 12.6 [Figure 1 above], if we interpret $P^{*}$ as the price level perceived or anticipated by workers. To them, it will appear as if the demand for labour had shifted to the right, to the dashed demand curve. At each nominal wage rate (also real wage as perceived by them), employers are seeking to hire more workers." (Friedman 1976: 224; his emphasis)

20 "Employers faced with an increased nominal demand for their products will count on being able to get a higher price or the equivalent. The same nominal wage means a lower real wage in terms of that higher price of his product. For employers as a whole, it will appear as if the supply curve had shifted to the right to the dashed supply curve." (Friedman 1976: 224).

21 It is usually believed that Lucas's Neutrality of Money model (Lucas [1972] 1981), which overhauled Friedman's model, rests on stronger information assumptions, the result of adaptive expectations being replaced by rational expectations. Yet, this is only part of the story. Actually, in Lucas's model, the domain of knowledge ascribed to agents is narrower than in Friedman's due to the presence of an auctioneer.
} 
Third, Friedman's natural rate of unemployment is nothing other than the quantity component of Marshallian normal equilibrium. In turn, the result described in Figure 2 can be viewed as a standard case of Marshallian disequilibrium, featuring a deviation of the market-day equilibrium values $\left(\mathrm{E}_{\mathrm{F}}, \mathrm{W}_{\mathrm{E}}\right)$ from their normal equilibrium values $\left(\mathrm{E}_{0}, \mathrm{~W}_{0}\right){ }^{22}$ Departures from the natural rate of employment rather than from the natural rate of unemployment are the real object of Friedman's model. Strictly speaking, there are no unemployed agents in his model but only agents who are temporarily over-employed with respect to normal equilibrium. 23

Friedman seems to be aware that something is wrong with this, yet he evades the issue by evoking frictional unemployment.

At the point of intersection $\mathrm{O}$, the market is in equilibrium at the wage rate $\mathrm{W}_{0}$, with the amount of labour employed $\mathrm{E}_{0}$, equal to the amount of labour demanded. Unemployment is zero - which is to say, as measured, equal to 'frictional' or 'transitional unemployment, or to use the terminology I adopted some years ago from Wicksell, at its 'natural' rate. (1976: 217).

But this resort to frictional unemployment is contrived. Frictional unemployment may well be meaningful in other types of models of the labour market yet not in the Marshallian, Friedman's reference. 24

The conclusion to be drawn is that Friedman's model significantly differs from his narrative. As the former should prevail over the latter, the elements that are present in the narrative yet absent from the model, in particular unemployment, should be eliminated. Recall Lucas's remark (quoted above) that equilibrium models of the business cycle evolve without resorting to the unemployment category. The same must be said about Friedman's Phillips Curve model. It abides by the equilibrium discipline, featuring both optimizing behaviour and market clearing. Hence it has no place for unemployment per se. If it departs from Lucas's model, it is on another point, namely its exhibiting a co-existence between market clearing and disequilibrium.

22 Friedman's unease in this respect is illustrated by his awkward use of the expression of 'overfull employment' (1976, 223).

23 This point has escaped the attention of most commentators. Tobin (1995) is an exception.

24 As aptly pointed out by Hahn, "Traditional search theory finds no formal representation of the economy in macro theories of the natural rate. It is referred to, or better appealed to, but it is not connected with the theory proposed" (1995: 52). See also Rogerson (1997) who confronts Friedman's categories with the search approach and makes it clear that his model is far from being a search model. 
From a methodological standpoint, Friedman's flaw lies in his unawareness of the fact that he is attributing economic agents the same knowledge of the constituants of the market as that held by the outside economist - more specifically, an ability to reconstruct market supply and demand functions.

A final, wider remark is worth making. I have claimed that Marshallian theory rests on the market-clearing postulate. This claim is verified in Friedman's model once this is disentangled from his realistically-slanted narrative. However, I do not want to claim that it is impossible to introduce market rationing in models having a Marshallian lineage. Let it be accepted that efficiency wage models can be characterised as having such a lineage. Their hallmark is to display an involuntary unemployment result. Is my analysis thereby invalidated? I do not think so. It is just that a subtler qualification of the concepts involved is required. To be specific, let me briefly comment on Shapiro and Stiglitz's well-known shirking model (1984).

My starting point is Lucas's association of individual equilibrium (optimising behaviour) with market clearing. In my analysis above, market equilibrium is considered the Marshallian incarnation of the Walrasian market-clearing notion. Whenever market equilibrium prevails, so does individual equilibrium. The originality of efficiency wage models is that they break the link between these notions. Market equilibrium, still associated with individual equilibrium, and market clearing have become diverging phenomena. That is, market clearing is no longer a necessary attribute of market equilibrium. However, the conclusion that the equilibrium discipline has been dispensed with should be avoided. It is just that its contents needs to be rephrased as consisting of optimising behaviour and market equilibrium, the latter now ceasing to go along with market clearing. Efficiency wages models are then a case where market rationing has indeed replaced market clearing. Nonetheless, they still abide by the equilibrium discipline, properly redefined.

\section{Concluding remarks}

In this paper I have addressed the issue of whether Marshallian theory abides by what Lucas pinpointed as the economic discipline, with special attention being given to its market clearing aspect. I have answered in the positive by claiming that the Marshallian equivalent to the Walrasian notion of market clearing is the matching of market supply and demand. However, my paper has shown that the matter is more complex than when the investigation bears on Walrasian theory. The first compounding factor is that the matching of market supply and demand can accompany disequilibrium, defined as a mismatch between normal supply and demand. Since at present most economists have in the back of their minds a 
Walrasian definition of equilibrium, where equilibrium and market clearing coincide, it is small wonder that they mistakenly extend the possibility of disequilibrium to that of market non-clearing. A second compounding factor is that Marshall held two conceptions of the formation of market equilibrium. When he came to address this issue specifically, he was able to present a rather realistic model allowing for "haggling and bargaining" and false trading. Yet, when it came to making an assumption about the formation of market equilibrium on which to base the study of normal equilibrium, it was agents' perfect information - the assumption that they were able to reconstruct market supply and demand functions - that did the job. In the latter case, there is no doubt that market clearing is always achieved. In the former, we have what could be called quasi-market clearing: the quantity traded is the same as in true equilibrium, and ditto for the price of the last transaction. The only difference is that agents' money holdings will differ from those they would otherwise have held.

All this leads me to conclude that Lucas and his associates have not invented market clearing but rather restored it. Their distinct contribution is to have changed its status, from a hidden premise to an explicit postulate. To me, this is an important methodological clarification. Should new classical theory be considered less original than claimed? Not necessarily. It is rather that its originality lies elsewhere. At this late stage, I must limit myself to a few broadbrushed remarks.

First of all, as already mentioned, new classicists have breached the gulf that earlier existed between value theory and business cycle theory - quite a feat. Second, accepting that macroeconomics is defined as pragmatic, simplified general equilibrium models, they may be credited with having invented 'Walrasian macroeconomics' to replace the earlier prevailing 'Marshallian macroeconomics'. 25 Third, Lucas and Sargent were right in stating that their approach is based on a different concept of equilibrium. The Marshallian approach rests on a standstill or stationary conception of equilibrium, the new classical on the Walrasian-Hicksian intertemporal conception. One important implication is worth mentioning. Associated with the stationary conception of equilibrium is the notion of "period of analysis": the economy or the market is studied over a period of time during which its basic data are supposed to remain unchanged, only accidental and reversible changes being accepted. The drawback of this way of positing issues is that economic change cannot be tackled in earnest. In contrast, this feature of unchanging fundamental data is no longer required in the intertemporal equilibrium approach, what permits to come to grips with the study of the economy "in time".

25 See De Vroey (2004b). 
All the above points suggest that new classical economics has made a progress with respect to Marshall. In contrast, the last difference that I wish to evoke points in the opposite direction. As I have shown, the fact that the Marshallian approach rests on the market clearing postulate does not preclude its addressing the issue of the working of competitive forces. Disequilibrium analysis, as understood in the Marshallian approach, is the study of competition. Things change when the duality of equilibrium concepts is dropped. Now the market-clearing postulate prohibits any study of how the invisible hand functions. What was once considered the main puzzle that economic theory had to solve - the efficiency of a decentralised economy - has become a foregone conclusion.

\section{References}

Arena, R. and M. Quéré (2003), eds. The Economics of Alfred Marshall: Revisiting Marshall's Legacy, New York: Palgrave Macmillan.

Dasgupta, A.K. (1990) “An Aspect of Marshall's Period Analysis” in Whitaker (ed.), pp. .242257

Clower, R. et A. Leijonhufvud ([1975] 1984), « The Coordination of Economic Activities : A Keynesian Perspective », in Walker (ed.), pp. 209-217.

De Vroey, M. (2004a), "Lucas on Involuntary Unemployment", Cambridge Journal of Economics, vol. 28, pp. 397-412.

De Vroey, M. (2004b), "The History of Macroeconomics Viewed Against the Background of the Marshall-Walras Divide", in M. De Vroey and K. Hoover (eds.), The IS-LM Model. Its Rise, Fall and Strange Persistence, History of Political Economy Annual Supplement, Duke University Press, pp. 57-91.

De Vroey, M. (2003), "Perfect Information à la Marshall versus Perfect Information à la Walras", Journal of Economic Methodology, vol. 10, pp. 465-492.

De Vroey, M. (2001), "Friedman and Lucas on the Phillips Curve: from a Disequilibrium to an Equilibrium Approach", Eastern Economic Journal, vol. 27, 127-148.

Friedman, M. (1976), Price Theory, Chicago: Aldine Publisher.

Friedman, M. (1968), “The Role of Monetary Policy”, American Economic Review, vol. 58, pp. 1-17.

Frisch, R. (1950), “Alfred Marshall's Theory of Value”, The Quarterly Journal of Economics, vol. 64, pp. 495-524.

Grandmont, J.-M. (1983), Money and Value: A Reconsideration of Classical and Neoclassical Monetary Theory, Cambridge: Cambridge University Press

Guillebaud, C. (1942), “The Evolution of Marshall's Principles of Economics', The Economic Journal, vol. 52, pp. 330-349.

Hahn, F. (1995), "Theoretical Reflections on the "Natural Rate of Unemployment'", in R. Cross, The Natural Rate of Unemployment. Reflections on 25 Years of the Hypothesis, Cambridge: Cambridge University Press, pp. 43-56.

Hayek, F. ([1937] 1948), "Economics and Knowledge", in Individualism and Economic Order, Chicago: The University of Chicago Press, pp. 33-55.

Hicks, J.R. (1965), Capital and Growth, Oxford: Clarendon Press.

Hicks, J. R. (1939), Value and Capital, Oxford: Clarendon Press (first edition). 
Jaffé, W. (1954,), Translators Notes, Walras, L. Elements of Pure Economics, , London: Allen and Unwin.

Leijonhufvud, A. (1998), "Mr. Keynes and the Moderns", The European Journal of the History of Economic Thought, vol. 5, pp. 169-88.

Lipsey, R. (2000), "IS-LM, Keynesianism, and the New Classicism", in Backhouse and Salanti, pp. 57-82.

Lucas, R. E. Jr. (1987), Models of Business Cycle, Basil Blackwell: Oxford.

Lucas R. E. Jr. and T. Sargent ([1979] 1994), "After Keynesian Macroeconomics" in Preston. R. Miller (ed.), The Rational Expectations Revolution. Readings from the Front Line, Cambridge: (Mass.): The M.I.T. Press, pp. 5-30.

Malinvaud, M. (1984), Mass Unemployment, Oxford: Basil Blackwell.

Marshall, A. (1920), Principles of Economics, London: Macmillan, (eight edition).

Mas-Collel, A., Whinston, M. and J. Green (1995), Microeconomic Theory, New-York, Oxford: Oxford University Press.

Matthews, R. C. O. (1990), "Marshall and the Labour Market", in Whitaker (ed.), pp. 14-43.

Negishi, T. (1989), History of Economic Theory, Amsterdam: North-Holland.

Newman, P. (1990), "The Great Barter Controversy", in Whitaker (1990), pp. 258-277.

Perloff J. (2001), Microeconomics (second edition), Addison, Wesley, Longman.

Rogerson, R. (1997), "Theory Ahead of Language in the Economics of Unemployment", Journal of Economic Perspectives, vol. 11, pp. 73-92.

Shapiro. C. and J. Stiglitz (1984), "Equilibrium Unemployment as a Worker discipline Device", American Economic Review, vol. 74, pp. 433-444.

Snowdon, B. and H. R. Vane (1998), "Transforming Macroeconomics: an Interview with Robert E. Lucas Jr.”, Journal of Economic Methodology, vol. 5, pp. 115-145.

Solow, R. (1990), The Labour Market as a Social Institution, Cambridge: Blackwell.

Stigler, G. (1946), The Theory of Price, New-York: Macmillan.

Tobin, J. (1995), "The Natural Rate as New Classical Macroeconomics", in Cross, R. (ed.), The Natural Rate of Unemployment. Reflections on 25 Years of the Hypothesis, Cambridge: Cambridge University Press.pp. 32-42.

Walker, D. (1996), Walras' Market Models, Cambridge: Cambridge University Press.

Walker D. (1984), (ed.) Money and Markets. Essays by Robert Clower, Cambridge University Press: Cambridge.

Walras, L. (1954), Elements of Pure Economics, translated by Jaffé W., London: Allen and Unwin.

Whitaker, J. K. (1987), "Marshall, Alfred (1842-1924)", The New Palgrave Dictionary of economics, London: Macmillan, vol. 3, pp. 350-363. 
Département des Sciences Économiques de l'Université catholique de Louvain

Institut de Recherches Économiques et Sociales

Place Montesquieu, 3

1348 Louvain-la-Neuve, Belgique 